\title{
Reviews
}

The Person and the Challenges

Volume 1 (2011) Number 2, p. 235-238

Robert Kantor

The Pontifical University of John Paul II in Cracow, Poland

\section{Przestrzenie pracy socjalnej (Espacios del trabajo social) bajo la dirección de prof. J. Stala, (ed.) Biblos Tarnów 2010, pp. 474, ISBN 978-83-733291-1-9}

Para la Doctrina social de la Iglesia, el trabajo significa todo tipo de acción realizada por el hombre independientemente de sus características o circunstancias; significa toda actividad humana que se puede o se debe reconocer como trabajo entre las múltiples actividades de las que el hombre es capaz y a las que está predispuesto por la naturaleza misma en virtud de su humanidad. Hecho a imagen y semejanza de Dios en el mundo visible y puesto en él para que dominase la tierra, el hombre está por ello, desde el principio, llamado al trabajo.

La profesión de trabajo social promueve el cambio social, la resolución de problemas en las relaciones humanas y el fortalecimiento y la liberación del pueblo para incrementar el bienestar. Mediante la utilización de teorías sobre comportamiento humano y los sistemas sociales, el trabajo social interviene en los puntos en los que las personas interactuan con su entorno. Los principios de los Derechos Humanos y la Justicia Social son fundamentales para el trabajo social.

El trabajo social en sus distintas expresiones se dirige a las múltiples y complejas relaciones entre las personas y sus ambientes. Su misión es la de facilitar que todas las personas desarrollen plenamente sus potencialidades, enriquezcan sus vidas y la prevención de las disfunciones. El trabajo social profesional está enfocado a la solución de problemas y al cambio. Por ello, los trabajadores sociales son agentes de cambio en la sociedad y en las vidas de las personas, familias y comunidades 
para las que trabajan. El trabajo social es un sistema de valores, teoría y práctica interrelacionados entre sí.

En el dinamismo diario, en el tiempo de las preguntas fundamentales y respuestas ligeras, crece la espera por las soluciones adecuadas, sabias sugerencias y estables puntos de referencia. Todo esto se refiere a la vida personal y social. Cada vez más se mira hacia el testimonio de acción, es decir testimonio de consecuencia y congruencia entre la fe y la vida. El testimonio de acción es un ejemplo de la responsabilidad: por las elecciones y acciones, las posturas, opiniones e ideas. Analizando las posturas del compromiso social de los católicos, se subraya la importancia de la fe en la vida personal de los católicos en sus actuaciones sociales. La fidelidad a la enseñanza de Cristo tiene mucha importancia en la vida social en este caso en el compromiso en la esfera social. La fe no se cierra en el interior del hombre, sino emana hacia lo exterior y lo cambia como el fermento hace la masa en la biblia. Por lo tanto hay que siempre preguntar por el compromiso de los cristianos - discípulos de Cristo, en el contexto de su compromiso en la vida de este mundo.

En un mundo actual cada vez más se subraya la posibilidad y necesidad de leer el orden de la creación, y también el orden en el mundo de las acciones humanas. La técnica, la vida económica, social, política exigen una preparación adecuada, competencia y preparación. A todo esto se espera en el lugar del trabajo, en el mundo social, económico y político. El dinamismo del mundo contemporáneo, marcado por el crecimiento técnico, la comunicación de la información como también la acción comunitaria de las comunidades humanas pone de relieve muchas preguntas dirigidas al hombre contemporáneo. Dichas preguntas se refieren al sentido de los cambios, de los cuales el hombre se presenta como autor. La observación de la vida nos permite ver, de que dichos cambios tienen lugar en muchos sectores de la vida humana. La creación de la vida social no se puede dejar a una „suerte", sino debería ser un efecto de razonable y responsable acción humana, inspirada por la luz de la fe. Entre otros, dichas cuestiones son objeto del amplio y profundo estudio „Espacios de la vida social” que forma parte, como siguiente volumen de la serie „Formación social” bajo la redacción de prof. Józef Stala.

Mencionadas antes cuestiones se cierran en dos partes. En la primera parte: „Entender” se encuentran los siguientes temas: Paweł Boryszewski, Cooperativa social para los minusválidos - una oportunidad perdida; Bogusław Drożdż, Dimensión cultural del trabajo social. Reflexión a la luz de la teológico-filosófica teoría de la cultura; Michał Drożdż, Condiciones de ingerencia del trabajo social; Mirosława Gawęcka, Acciones de ayuda en el trabajo social e implicaciones 
del beneficiente como su destinatario; Grzegorz Grzybek, Trabajo social en los principios de „la ética del desarrollo”; Tadeusz Kamiński, Retos éticos del trabajo social en Polonia; Marek Kluz, Vejez y sus problemas en la civilización contemporánea; Dariusz Lipiec, Iglesia frente al problema de la normalización de los minusválidos; Elżbieta Osewska, Józef Stala, Indicaciones referidas al trabajo con los minusválidos como resultado del „Programa de la educación de la religión católica en la escuelas de los párvulos y escuelas" del año 2010; Władysław Szewczyk, Ayuda competente exige sabiduría, habilidad y valor; Teresa Zbyrad, Entre profesión y servicio - sobre dificultades de ayuda de un trabajador social; Marian Stepulak, Secreto profesional del trabajador social. En cambio en la segunda parte: „Actuar” se presentan temas: Piotr Chrabąszcz, Trabajo social frente a los que se hacen depender; Anna Fidelus, Apoyo social como exigencia de la readaptación eficaz de los antiguos condenados; Artur Filipiak, Servicial carácter de la catequesis de las personas que pasan por los cambios y crisis de la vida; Stanisław Garnczarski, Elementos de la musicoterapia como ayuda en el trabajo social. Andrzej Kiciński, Objetivos del trabajo caritativo - social en los Círculos de Cáritas en los pueblos y ciudades; Anna Kołakowska, Hospital como lugar de la formación de las relaciones entre humanos. Comunicación de las investigaciones; Marta Kowalczyk, Prioridades en el trabajo caritativo con los minusválidos físicamente en el grado importante; Anna M. Kruk, Empleo social como una oportunidad del trabajo profesional fuera del llamado abierto empleo; Józef Młyński, Necesidad de funcionamiento y diágnosis de la acividad de los trabajadres sociales en las elegidas Casas de Ayuda Social en el distrito de Tarnów; Wojciech Osial, Hombre viejo en la familia - análisis de los retos para la formación religiosa del jóven hombre; Danuta M. Piekut-Brodzka, Aprovechar la ayuda en el peiodo sin hogar - resultados de la investigación; Małgorzta Duda, Hombres sin hogar - reto moral de la sociedad; Leszek Rojowski, Cáritas de la Iglesia en la Semana de la Misericordia. Historia de las primeras Semanas de Misericordia antes de la segunda guerra mundial en la diócesis de Tarnów; Ryszard Podstołowicz, Piotr Grzanka, „Reto: ayudar sobrevivir la crisis”. Cáritas de la diócesis de Tarnów para la gente necesitada; Bożena Sidor-Piekarska, Organizaciones no gubernamentales en la situación de ayuda a los padres del niño minusválido mentalmente; Stanisław Sojka, Etos del trabajador social y su postura frente a la violencia; Andrzej Sułek, Ayuda en el luto como un reto del trabajador social; Anna Zellman, Participación del maestro de la religión en la organización del voluntariado escolar - posibilidades y retos pedagógicos y catequéticos. 
El trabajo social se enfrenta a las fronteras, desigualdades e injusticias que existen en la sociedad. Responde a las crisis y emergencias así como a las problemas personales y sociales del día a día. Utiliza distintos conocimientos, técnicas y actividades consecuentes con su centro de atención holístico en las personas, por un lado y en sus entornos por otro. Las intervenciones de trabajo social abarcan desde los procesos psicosociales focalizados a nivel individual, hasta el compromiso con la política, la planificación y el desarrollo sociales. Estos incluyen el asesoramiento, el trabajo social de casos, el trabajo social con grupos, la pedagogía social y la tratamiento y terapia familiar, así como esfuerzos para ayudar a las personas a obtener servicios y recursos comunitarios. Las intervenciones también incluyen la dirección de organismos, organización comunitaria y el compromiso con la acción sociopolitica para influir en la política social y el desarrollo económico.

La monografía bajo la dirección de prof. Stala a parte de las consideraciones anteriores tiene otro valor importante, es decir, nos ayuda entender mejor que en e futuro se deberá garantizar el acceso al trabajo y a la profesión sin discriminación injusta, a hombres y mujeres, sanos y disminuidos, autóctonos e inmigrados. La sociedad debe por su parte ayudar a los ciudadanos a procurarse un trabajo y un empleo. A todos los lectores les recomiendo esta obra editada en Tarnów. 